\title{
Propeller-type parallel-stranded G-quadruplexes in the human $c$-myc promoter
}

\author{
Anh Tuân Phan*, Yasha S. Modi and Dinshaw J. Patel \\ Structural Biology Program, \\ Memorial Sloan-Kettering Cancer Center \\ New York, NY 10021, USA
}

\section{Supplementary Materials}

*Corresponding author

Phone: (212)-639-2772; Fax: (212)-717-3066; e-mail: phantuan@ mskcc.org

Running title: Parallel-stranded G-quadruplexes in the $c-m y c$ promoter

Key words: double-chain-reversal loops; G-quadruplex polymorphism; parallel-stranded Gquadruplexes; $c$-myc promoter 


\section{SUPPLEMENTARY FIGURE LEGENDS}

Figure S1. Aromatic proton spectra of: (a) myc-2345; (b) myc-1245. Line-widths of the sharpest peaks are shown. Experimental conditions: strand concentration, $1 \mathrm{mM}$; temperature, $25^{\circ} \mathrm{C} ; 70$ $\mathrm{mM} \mathrm{KCl}$; potassium phosphate, $20 \mathrm{mM}$; pH 7.

Figure S2. One-dimensional $600 \mathrm{MHz}$ proton spectra at different temperatures of (a) myc-2345 and (b) myc-1245, showing the G-quadruplex structured (labeled with "x") and unfolded (labeled with “\#”) forms. At $63{ }^{\circ} \mathrm{C}$ (and $47^{\circ} \mathrm{C}$ ), the fraction of the myc-2345 (and myc-1245) propellertype G-quadruplex is equal to the fraction of the unfolded form. At $75^{\circ} \mathrm{C}$, the G-quadruplex form of myc-1245 is completely unfolded, that of myc-2345 retains about $10 \%$ of the folded conformation. Experimental conditions: strand concentration, $0.15 \mathrm{mM} ; 7 \mathrm{mM} \mathrm{KCl}$; potassium phosphate, $2 \mathrm{mM}$; pH 7.

Figure S3. Assignment of guanine H8 protons of (a, a') myc-2345 and (b, b', b') myc-1245 by $\left[{ }^{1} \mathrm{H}_{-}{ }^{15} \mathrm{~N}\right]$ long-range and $\left[{ }^{1} \mathrm{H}^{-13} \mathrm{C}\right]$ one-bond correlation experiments, respectively. The reference spectra of unlabeled myc-2345 and myc-1245 samples are shown in (a) and (b). Spectra of myc$23452 \%-{ }^{15} \mathrm{~N}$-labeled at G16 and $m y c-12452 \%-{ }^{15} \mathrm{~N},{ }^{13} \mathrm{C}$-labeled at G5 and G23 are shown in (a'), (b'), and (b"), respectively. Peaks from minor components are labeled with a star. Experimental conditions: strand concentration, $1 \mathrm{mM}$; temperature, $25^{\circ} \mathrm{C} ; 70 \mathrm{mM} \mathrm{KCl}$; potassium phosphate, $20 \mathrm{mM}$; pH 7. 


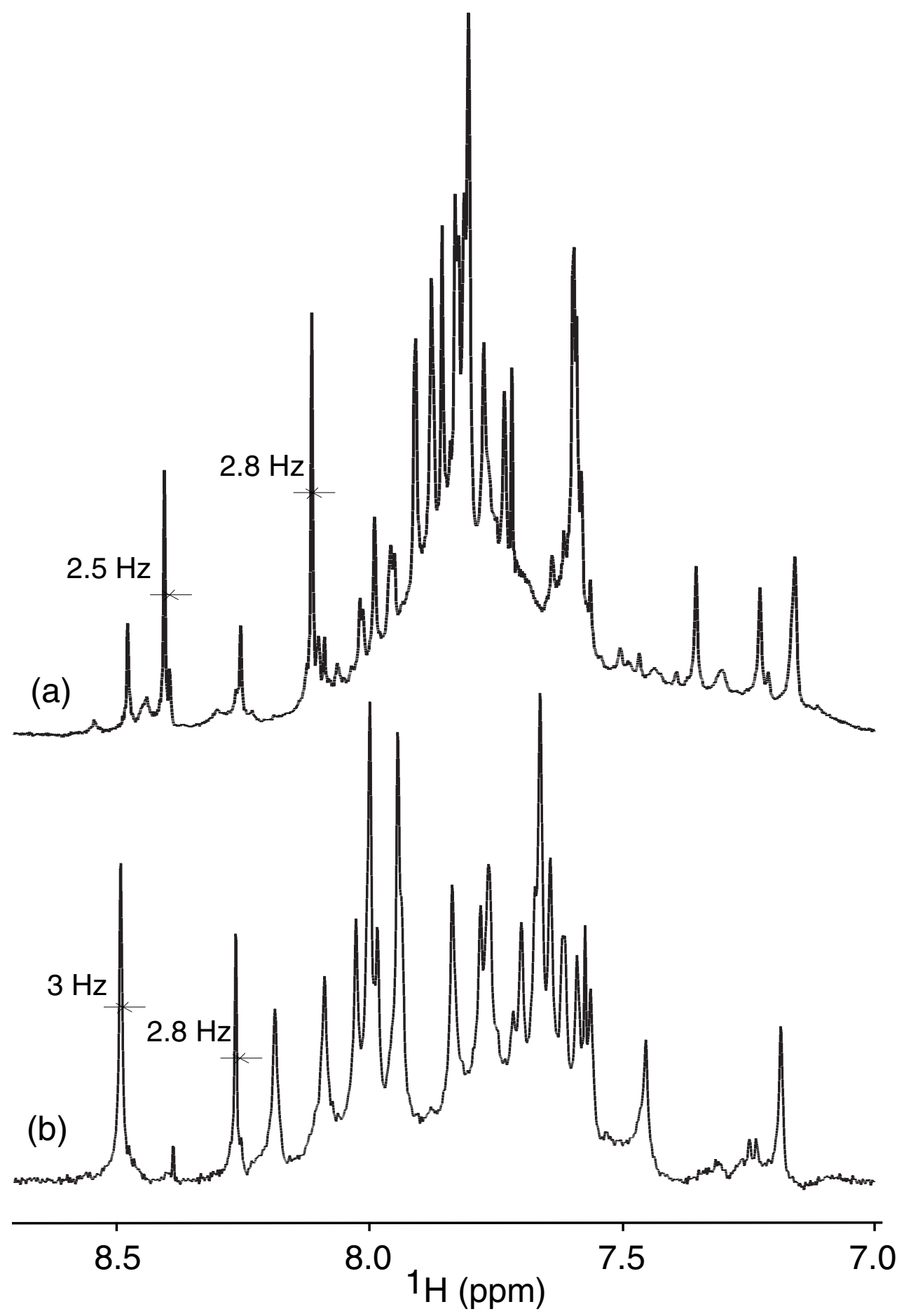

Fig. S1 
(a)

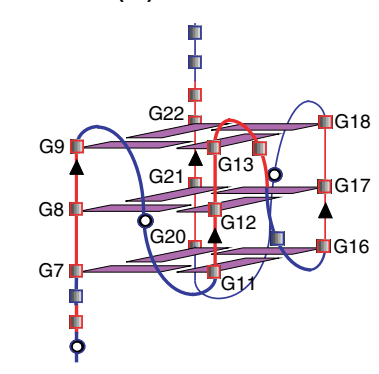

Imino protons

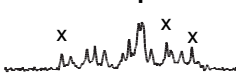

Hond

11
Aromatic protons

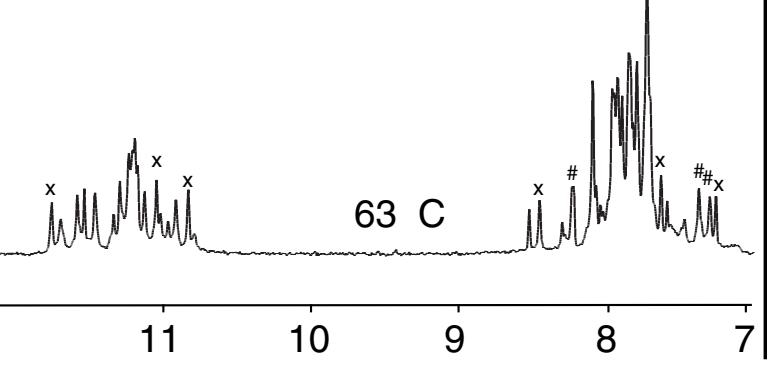

(b)
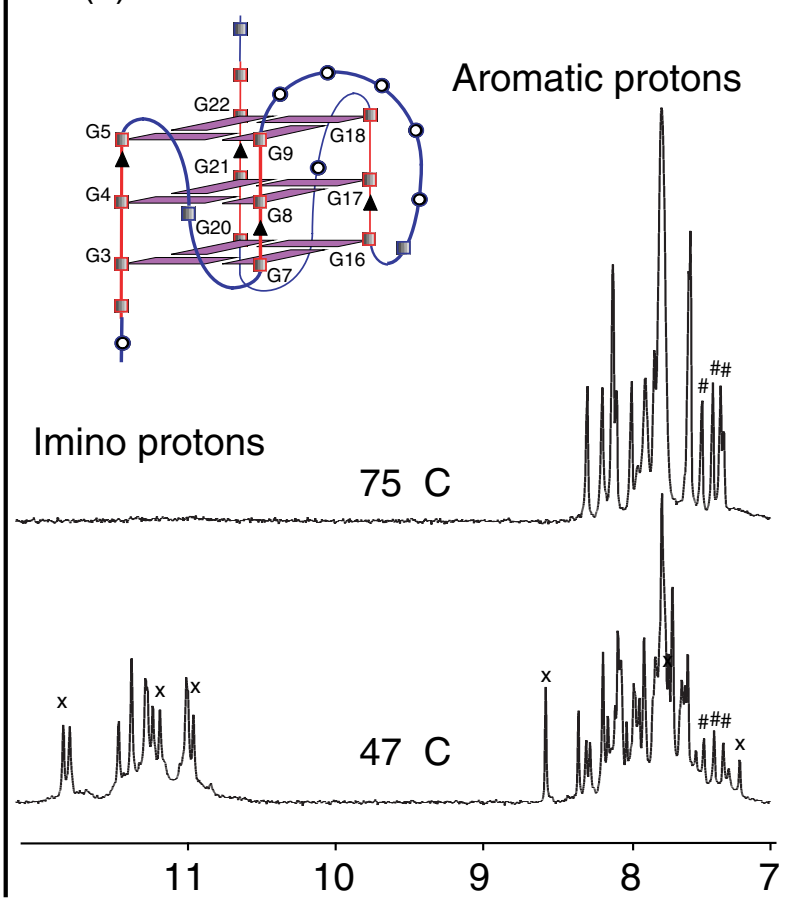

$\mathrm{H}$ (ppm)

Fig. S2 

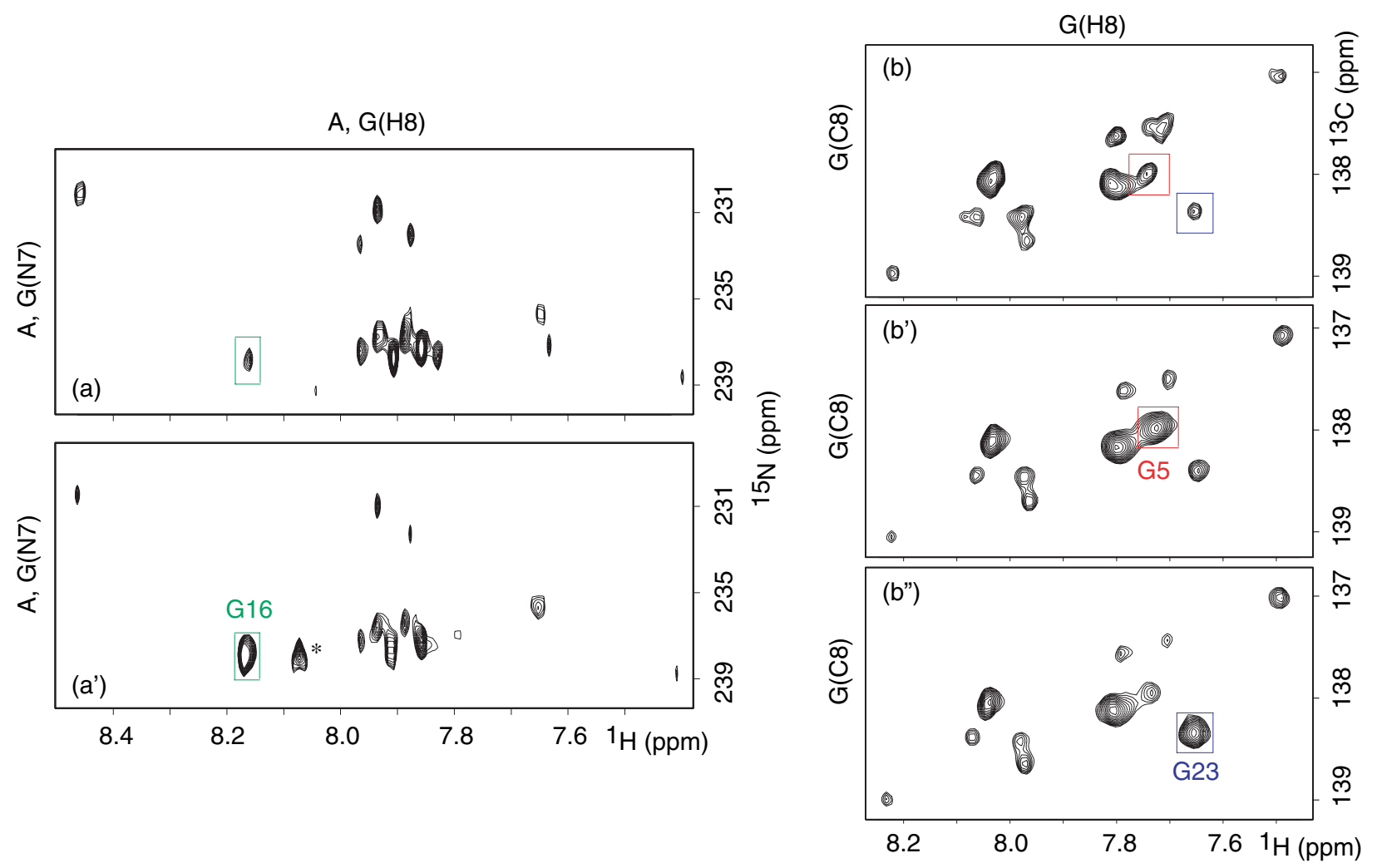

Fig. S3 